OPEN ACCESS

Edited by:

Giorgio Sandrini,

University of Pavia, Italy

Reviewed by:

Rocco Salvatore Calabrò

Centro Neurolesi Bonino Pulejo

(IRCCS), Italy

Andrew C. Smith,

University of Colorado, United States

${ }^{*}$ Correspondence:

Davide Dalla Costa

davide.dallacosta@ospedaleniguarda.it

Specialty section

This article was submitted to

Neurorehabilitation,

a section of the journa

Frontiers in Neurology

Received: 03 September 2020

Accepted: 02 December 2020

Published: 07 January 2021

Citation:

Colonna S, Sciumé L, Giarda F,

Innocenti $A$, Beretta $G$ and Dalla

Costa D (2021) Case Report:

Postacute Rehabilitation of

Guillain-Barré Syndrome and Cerebral

Vasculitis-Like Pattern Accompanied

by SARS-COV-2 Infection.

Front. Neurol. 11:602554.

doi: 10.3389/fneur.2020.602554

\section{Case Report: Postacute Rehabilitation of Guillain-Barré Syndrome and Cerebral Vasculitis-Like Pattern Accompanied by SARS-CoV-2 Infection}

\author{
Stefano Colonna ${ }^{1}$, Luciana Sciumé ${ }^{1}$, Federico Giarda ${ }^{1}$, Alessandro Innocenti ${ }^{2}$, \\ Giovanna Beretta ${ }^{1}$ and Davide Dalla Costa ${ }^{1 *}$ \\ 'Department of Rehabilitation Medicine and Neurorehabilitation, ASST Grande Ospedale Metropolitano Niguarda, Milan, \\ Italy, ${ }^{2}$ Department of Neurology and Stroke Unit, Niguarda Ca' Granda Hospital, Milan, Italy
}

Introduction: The main clinical manifestation of the novel Severe Acute Respiratory Syndrome Coronavirus-2 (SARS-CoV-2) is respiratory issues. Neurological manifestations are being increasingly recognized, including febrile seizures, headache, dizziness, and myalgia, as well as encephalopathy, encephalitis, stroke, and acute peripheral nerve diseases. Cerebral vasculitis is rarely reported. We describe a case of SARS-CoV-2 interstitial pneumonia complicated by flaccid tetraplegia due to Guillain-Barré Syndrome (GBS) associated with a cerebral vasculitis-like pattern.

Case description: A 62-year-old man was hospitalized for cough, fever, and severe respiratory failure requiring tracheal intubation and invasive ventilation. The chest Computerized Tomography (CT) showed images related to interstitial pneumonia and the subsequent nasopharyngeal swab confirmed the presence of SARS-CoV-2 infection. During the hospitalization, there was a progressive deterioration of the senses associated with areflexic flaccid tetraplegia. The treatment with high doses of immunoglobulin $\mathrm{G}$ (lgG) led to the immediate improvement of the general conditions and a partial response in terms of recovery of the upper limb and of the distal lower limb movements. Subsequently the patient was admitted to our Rehabilitation Unit, where he received an intensive rehabilitation treatment consisting of physiotherapy and occupational therapy. Two months later the patient was discharged at home and able to walk independently even for long distances thanks to the use of Ankle-Foot Orthosis (AFO).

Conclusion: In this report, we present the case of a patient with peripheral and central neurological damage occurred later severe pneumonia induced by SARS-CoV-2. The Immunoglobulin $G$ therapy allowed the patient to benefit considerably from early rehabilitation, reaching the walking, increasing the independence in daily living tasks, and enabling safe discharge from hospital to home. Related neurologic complications of SARS-CoV-2 infection suffer a lack of understanding and further investigations should be conducted.

Keywords: SARS-CoV-2, Guillain-Barré syndrome, polyradiculonevritis, cerebral vasculitis, rehabilitation 


\section{INTRODUCTION}

Since the appearance of the first case of coronavirus disease 2019 (COVID-19), the spread of infection has quickly affected millions of people worldwide, and was declared a pandemic by the World Health Organization in March 2020 (1). Severely symptomatic patients may present with pneumonia, acute respiratory distress syndrome (ARDS), acute cardiac dysfunction from myocarditis, and multiorgan failure (2). Although the main clinical presentation is respiratory disease, there is emerging evidence that SARS-CoV-2 infection could be associated with neurological complications, including febrile seizures, headache, dizziness, and myalgia, as well with encephalopathy, encephalitis, stroke, and acute peripheral nerve diseases (3). Cerebral vasculitis is rarely reported $(2,4)$. features appear to be a combination of nonspecific complications of systemic disease, the effects of direct viral infection, or inflammation of the nervous system and vasculature, which can be para-infectious or post-infectious (4). We aim to report a case of COVID-19 complicated by GuillainBarré Syndrome (GBS) and central nervous system involvement resembling vasculitis.

\section{CASE DESCRIPTION}

The patient is a 62-year-old man without significant medical history, suffering from high blood pressure and obesity, who was hospitalized between April 2020 and July 2020 in the Neuroscience department of the ASST Grande Ospedale Metropolitano Niguarda 'Ca Granda in Milan (Italy). On March 17, 2020 the patient was admitted to the Emergency Room of Clinica Polispecialistica in Paderno Dugnano in Italy. He presented with a fever and cough that had been persisting for about a week and that progressively worsened. He was alert and cooperative, without neurological interest. Gastrointestinal symptoms were not recently experienced. At the entrance, hemogasanalysis parameters showed an acute severe respiratory alkalosis: pH: 7.54 - pCO2: $32 \mathrm{mmHg}$ - pO2: $26 \mathrm{mmHg}$. Chest Computerized Tomography (CT) showed images of interstitial pneumonia with multiple foci in a consolidative evolution and bilateral pleural effusion. Because of this, and considering the clinical suspicion of infection with SARSCoV-2, a reverse-transcriptase polymerase-chain-reaction (PCR) oropharyngeal swab was performed that confirmed the diagnosis. The patient was transferred to the Intensive Care Unit (ICU) where, at first, he was treated with Continuous Positive Airway Pressure (CPAP), but subsequently intubation was required to improve respiratory gas exchange. He was treated with antibiotic therapy (Piperacillin and Tazobactam $6.75 \mathrm{mg} /$ day for 12 days, Vancomycin $2 \mathrm{~g}$ /day for 8 days, Ceftriaxone 2 g/day for 2 days), antiretrovirals (Darunavir/Ritonavir 800/100 $\mathrm{mg} /$ day for 12 days), corticosteroid (Methylprednisolone $60 \mathrm{mg}$ for 25 days), and Low-molecular-weight heparin (LMWH Enoxaparin 2000 IU 2 times for day). Despite concomitant cardiological complications (atrial fibrillation associated with high ventricular response - Heart Rate: 190 beats/min), severe anemia (hemogasanalysis parameters: hemoglobin $(\mathrm{Hb}): 5.9 \mathrm{~g} / \mathrm{dl}$ - hematocrit (Ht): 19\% on March 30), and acute renal failure
(Creatinine level: $4.40 \mathrm{mg} / \mathrm{dl}$ - estimated glomerular filtration rate (eGFR): $13.6 \mathrm{~mL} / \mathrm{min} / 1.73 \mathrm{~m}^{2}$ - blood urea nitrogen level: $192 \mathrm{mg} / \mathrm{dl}$ on March 31) improvement of clinical condition and respiratory distress was recorded. On March 20 he was extubated and continued the hospital stay in the General Medicine Department of the same hospital. Figure 1 shows the timeline of symptoms, diagnostic, interventions, and outcomes.

\section{Diagnostic Assessment and Pharmacological Therapies of Neurological Disorder}

Starting from April 1, a progressive worsening of neurological involvement characterized by sensory deterioration associated with flaccid quadriplegia areflexic was detected. For this reason, the patient was transferred to the emergency room of another hospital in Legnano, where more diagnostic exams were performed. The Brain Magnetic Resonance Imaging (MRI) showed two subcortical lesions in the parietal and left occipital sites, with restriction in Diffusion-Weighted Imaging (DWI) and without contrast enhancement. Rare point-like microbleeds without restricted diffusion were also detected in the white matter of both the cerebral lobes, interpreted as suggestive of previous ischemic lesions. Cerebrospinal fluid (CSF) assessment revealed an albuminocytologic dissociation with increased glucose (166 $\mathrm{mg} / \mathrm{dl}$, normal $45-80 \mathrm{mg} / \mathrm{dl}$ ), protein level $(51 \mathrm{mg} / \mathrm{dl}$, normal 8-43 mg/dl), and no cells. SARS-Cov-2 RNA was not tested in CSF. Electrophysiological studies were performed: the common peroneal nerve showed no excitation on the left and marked lower amplitude of nerve conduction on the right, as well as a conduction block at the popliteal fossa. Significantly prolonged distal motor latencies and temporal dispersion of the compound muscle action potentials (CMAP) at four limbs muscles, absent F-waves, and reduced motor nerve conduction of the tibial, median, and ulnar nerves on both sides were recorded, as well as slightly reduced sensory potential amplitude size. Sensory conduction pathways of the median, ulnar, and sural nerves were normal. Electromyography (EMG) needle electrode showed no denervation signs. Motor unit recruitment was not assessable. The findings described were consistent with the diagnosis of acute inflammatory polyradiculoneuritis. On the basis of these results, the diagnosis of Guillain Barré Syndrome (GBS; Acute Inflammatory Demyelinating Polyneuropathy or AIDP variant) was done. In this context, we hypothesized that AIDP could be the result of an autoimmune reaction in the course of infection with SARS-CoV-2 $(5,6)$. Once more the patient was intubated then treated with high-dose Intravenous Immunoglobulin (2 $\mathrm{g} / \mathrm{kg}$ from April 5 to April 10). GBS prognosis can be estimated by applying the modified Erasmus Guillain-Barré Syndrome outcome score (mEGOS) $(7,8)$. The results were $8 / 9$ at admission and $11 / 12$ at day 7 of hospitalization, pointing to a poor outcome. Negative mood and sometimes depression were reported mainly due to loss of autonomy and complete dependence on ADLs. On April 12, after extubation, the hospital stay continued in the General Medicine Department, where he underwent hemodialysis for acute renal failure on April 15 (Creatinine level $5.50 \mathrm{mg} / \mathrm{dL}$ and diuresis of $500 \mathrm{ml}$ in $24 \mathrm{~h}$ ). On May 6, general 
A 62-year-old man was admitted to Emergency Room presenting cough and fever since one week. Unremarkable medical history, except for obesity and hypertension. He was alert and cooperative, without neurological interest.

\begin{tabular}{|l|}
\multicolumn{1}{|c|}{ DIAGNOSTIC TEST } \\
\hline \multicolumn{1}{|c|}{ Emergency Room } \\
Hemogasanalysis test: \\
acute severe respiratory insufficiency \\
Chest Computerized Tomography (CT): \\
interstitial pneumonia - multiple foci - bilateral pleural \\
effusion. \\
Reverse-transcriptasepolymerase-chain-reaction (PCR) \\
Oropharyngeal test: SARS-CoV-2 infection positivity \\
\hline
\end{tabular}

\begin{tabular}{|c|}
\hline Areflexic flaccid tetraparesis \\
\hline $\begin{array}{l}\text { Brain Magnetic Resonance Imaging (MRI): } \\
\text { two subcortical lesions in parietal and left occipital } \\
\text { sites, rare micro-bleeds } \\
\text { Electrophysiological studies-electromyography (EMG): } \\
\text { findings of acute demyelinating polyneuropathy } \\
\text { Cerebrospinal fluid (CSF) examination: } \\
\text { albuminocytologic dissociation, } \\
\text { increased proteins and no cells }\end{array}$ \\
\hline Diagnosis: Guillain-Barré Syndrome \\
\hline $\begin{array}{l}\text { MRI - first control } \\
\text { Lesions Interpreted as vasculitic rather than embolic }\end{array}$ \\
\hline $\begin{array}{l}\text { EMG - first control } \\
\text { serious damage of Superficial Fibular (Peroneal) Nerve } \\
\text { associated with slight suffering of the Deep Fibular } \\
\text { (Peroneal) Nerve bilaterally }\end{array}$ \\
\hline
\end{tabular}

17 March

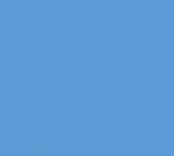

20 March

\section{MEDICAL TREATMENTS}

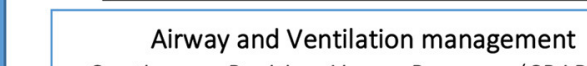

- Continuous Positive Airway Pressure (CPAP)

- Tracheal Intubation - First Intubation

Antibiotics and corticosteroid

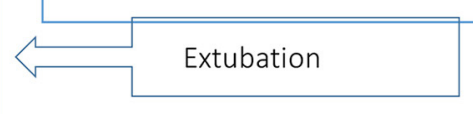

1 April

3 April

5 April

THERAPY

12 April

Second Intubation

THERAPY

high-dose Intravenous Immunoglobulin $\operatorname{lgG}(2 \mathrm{~g} / \mathrm{kg}$ for 5 days $)$

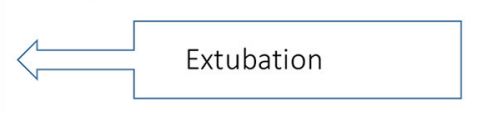

\section{REHABILITATION TREATMENTS}

6 May

8 PCR-oropharyngeal test: negative the patient was alert and conscious, no fever and cough

29 May

T0 - functional evaluation Poor trunk control, standing and walking impossible TRAINING to prevent imbalance and falls

\section{June}

T1 - functional evaluation

Trunk postural control $\rightarrow$ reached transfer independently $\rightarrow$ reached Upright stance $\rightarrow$ with support and assistance Ankle stability and proprioception $\rightarrow$ improved TRAINING to use walking aids (walker), coordination exercises and aerobic activities

10 July

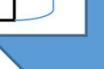

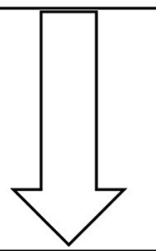

20 July

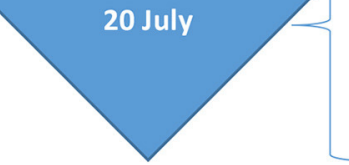

$\underline{\text { T2 functional evaluation }}$

Upright stance $\rightarrow$ without aids

Walking $\rightarrow$ independent over short distances

with aids (walker) and AFO

Patient completed the comprehensive inpatient rehabilitation, continuing his recovery in our outpatient service. Independence in basic activities of daily living (ADL), except for needing supervision on taking a shower, was achieved. He expressed his happiness recognising the efficacy of drug therapies and rehabilitation treatments.

FIGURE 1 | Timeline of symptoms, diagnostic, interventions, and outcomes. 
health condition was stable. The muscle strength enhanced, although weakness of the proximal upper limb and of the distal lower limb remained relevant. Consequently, he was admitted to our Rehabilitation Unit (RU) to continue the recovery.

\section{Rehabilitation Assessments and Treatments}

At admission the patient was alert and conscious, body temperature was $37.2^{\circ} \mathrm{C}$, there was no cough, and the last PCRoropharyngeal test was negative. Vital signs' measurements were: blood pressure: 125/70 $\mathrm{mm} \mathrm{Hg}$, heart rate: 74 beats/min, and oxygen saturation: $95 \%$ on room air. Standard laboratory tests detected white blood cells count (17.600), $\mathrm{Hb}(8 \mathrm{~g} / \mathrm{dl})$, c-reactive protein $(6.5 \mathrm{mg} / \mathrm{dl})$, creatinine level $(4.8 \mathrm{mg} / \mathrm{dl})$, and blood urea nitrogen level $(117 \mathrm{mg} / \mathrm{dl})$. Erythropoietin was prescribed to treat anemia. No electrocardiographic changes were visible. At the neurological examination cranial nerves were intact and no speech disorders or swallowing problems were noticeable. All sensations were preserved. Motor clinical assessment was characterized by a marked loss of muscle mass and tetraparesis, evident in the proximal upper and lower limbs (strength muscle was of grade $3 / 5$ at deltoid, biceps, extensor carpi radialis, iliopsoas, and quadriceps) and more intense at ankle dorsiflexor muscles (grade 0/5 at anterior tibial muscles), as measured by the British Medical Research Council muscle strength grading system (9). Deep tendon reflexes were absent; muscle tone was normal in four limbs. Depressive symptoms described during ICU stay were reduced: drug therapy (Citalopram, $20 \mathrm{mg} /$ day), psychological support, and contacts with family members, once a day because of COVID-19 restrictions, gradually had a positive effect on emotions. In order to monitor rehabilitation effectiveness and outcomes, the staff applied the following measurements: Modified Rankin Scale (MRS) (10), Modified Barthel Index (MBI) (11), Trunk Control Test (TCT) (12), Short Physical Performance Battery (SPPB) (13), Berg Balance Scale (BBS) (14), Time-Up and Go (TUG) (15), and 6 Min Walking Test (6MWT) (16). The first evaluation was performed on May 7 (T0) and the final one on July 20 (T2). An intermediate assessment was carried out on June 10 (T1) when it was possible to administer all the tests. The early rehabilitation program consisted of, twice a day, a 45 min' physiotherapy (PT) session alternated with 30 min' occupational therapy (OT) for 6 days a week. At the first stage, the trunk control was poor in a sitting position and the patient needed assistance in transfers, thus a standing position and walking were not possible. Rehabilitation programs were initially aimed to prevent deconditioning and development of skin ulcers, as a result of bed rest and physical inactivity, and muscle shortening and joint contracture, as consequence of motor weakness. Proper bed positioning with frequent postural changes, and sitting posture on the bed through back support and on a wheelchair were provided. Time to sit was gradually increased up to $4 \mathrm{~h}$ per day after a week. To reduce fatigue, pulmonary rehabilitation included breathing control, chest-abdominal coordination exercises to stimulate a proper recruitment of the diaphragm muscle, and positive expiratory pressure (PEP) bottle exercise to increase the pulmonary volume. To improve muscle mass and power, initial exercises included gentle strengthening involving isometric manual-resistive exercises, followed by upper and lower limb active exercises and manual progressive resistive mobilization, carefully tailored to the clinical condition of the patient. After 10 days, trunk postural control was achieved and a few days later the ability to transfer independently was also gained. When the upright stance was reached with support and assistance of the PT/OT, more specific training was set up to prevent imbalance and falls. This training involved balance in static and dynamic conditions and active exercises of lower limb and trunk muscles. Due to impaired ankle stability, great care to proprioception (sense of body position and movement) was taken (T1 - 1 month later). In the last month (T2 - 2 months later) the rehabilitation program focused on walking recovery, at the beginning over short distances with supports, assistance, and Ankle-Foot Orthoses (AFO) to contrast bilateral foot drop, then by learning to use walking aids (walker). Coordination exercises and aerobic activities were involved to reach the best performance.

\section{Diagnostic Follow-Up}

A first control MRI was checked on May 8 (Figures 2A-E). The exam displayed small T2 fluid-attenuated inversion recovery (FLAIR) focal hyperintensities in the subcortical white matter with restricted diffusivity in the left occipital and parietal cortex (IMG); due to the size and location, the multiple lesions were interpreted as vasculitic rather than embolic. On June 16, the neuroimaging features between the first and second MRI were unchanged, showing ischemic lesions in the left parietal and occipital lobes without restricted diffusion and still suggestive for vasculitic-like lesions (Figures 2F,G). The EMG of May 29 , additionally, corroborated the diagnosis of GBS, defined by serious damage of the Superficial Fibular (Peroneal) Nerve associated with slight bilateral suffering of the Deep Fibular (Peroneal) Nerve (Table 1).

\section{Outcomes of Rehabilitation}

The rehabilitation process promoted a gradual increase of strength muscle and led to functional recovery. Assessment results are presented in Table 2 . Walking was initially possible with the support of a four-wheeled walker for medium distances (6MWT: 237 meters) with walking speed of $2.37 \mathrm{Km} / \mathrm{h}$, using two Ankle-Foot Orthoses (AFO), as a consequence of bilateral weakness in the ankle dorsiflexion and plantarflexion. At discharge, 75 days after admittance to our RU, the patient achieved the restoration of strength performance at proximal limb muscles (grade 5/5), however muscle weakness of ankle and toes dorsiflexion persisted (grade 3/5 on the right; grade $1 / 5$ on the left). Balance control was upgraded (BBS: 50/56), as well as walking technique and aerobic endurance. Wearing AFOs, but without assistance or aid, he walked for long distances (6MWT: 345 meters) with a speed of $3.45 \mathrm{Km} / \mathrm{h}$. Independence in basic activities of daily living (ADLs), except for needing supervision on taking a shower, was achieved. After completing the comprehensive inpatient rehabilitation, he continued his recovery in our outpatient service. 

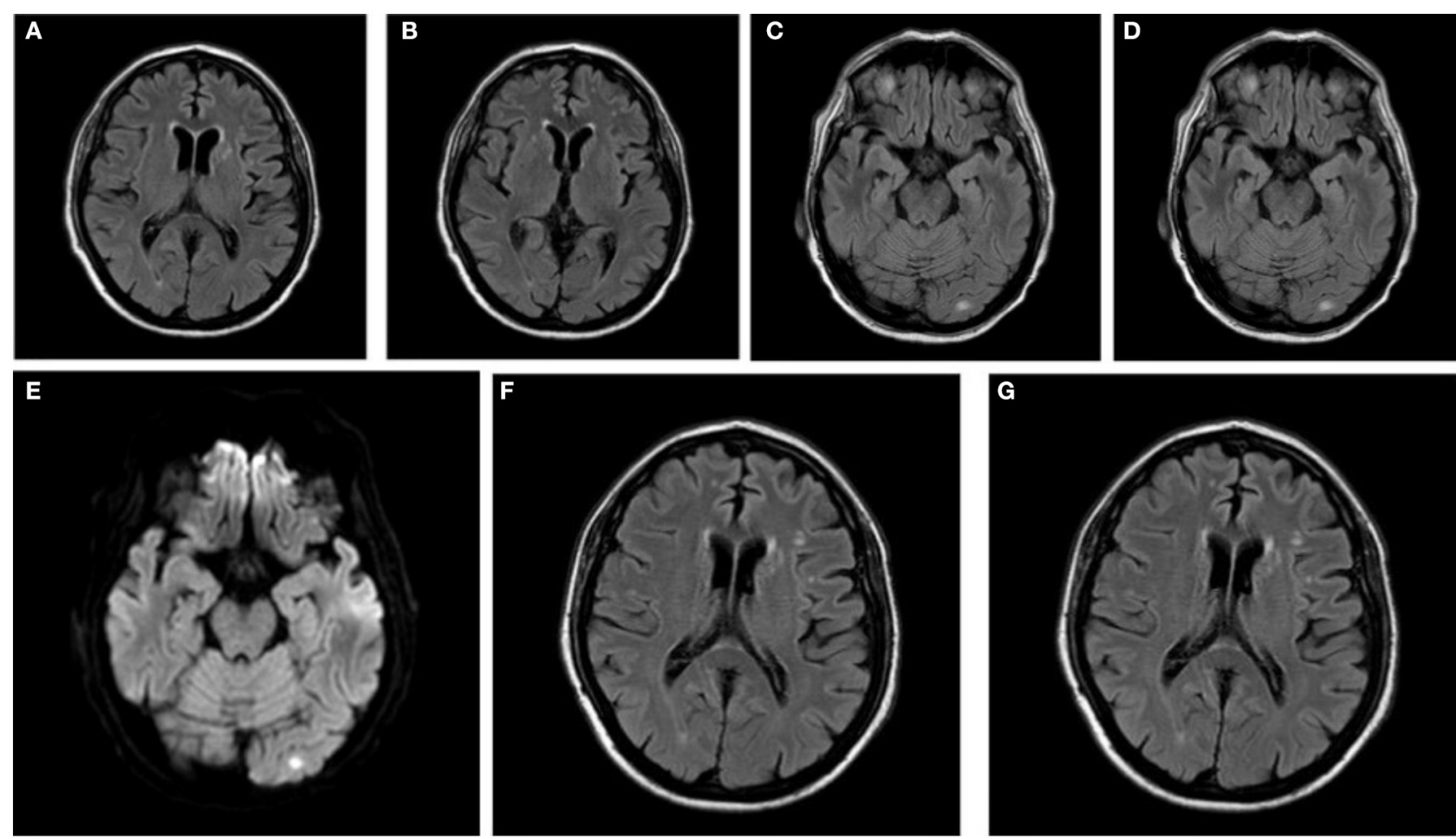

FIGURE 2 | Shoot from brain MRI of May 8 in (A-E): (A,B) show T2-FLAIR acquisition. (C) Shows occipital lesion in T2-FLAIR acquisition. (D) Shows parietal lesion in T2-FLAIR acquisition. (E) Shows occipital lesion positive in DWI. Shoot from Brain MRI of June 16: (F,G) show T2-FLAIR acquisition.

TABLE 1 | Summary table of results of electromyographic examination of May 29.

\begin{tabular}{|c|c|c|c|c|c|c|c|c|c|}
\hline \multirow[b]{2}{*}{ Muscle } & \multicolumn{5}{|c|}{ Spontaneous } & \multicolumn{3}{|c|}{ MUAP } & \multirow{2}{*}{$\begin{array}{l}\text { Recruitment } \\
\text { Pattern }\end{array}$} \\
\hline & IA & Fib. & PSW & Fasc. & H.F. & Amp. & Dur. & PPP & \\
\hline L. Tib. Anterior & $N$ & $3+$ & $3+$ & None & None & - & - & - & Absent \\
\hline L. Ext. Dig. Brevis & $\mathrm{N}$ & $3+$ & $3+$ & None & None & - & - & - & Absent \\
\hline R. Ext. Dig. Brevis & $\mathrm{N}$ & $3+$ & $3+$ & None & None & $\mathrm{N}$ & $\mathrm{N}$ & $\mathrm{N}$ & Absent \\
\hline L. Gastrocn (Med) & $\mathrm{N}$ & None & None & None & None & $2+$ & $1+$ & $2+$ & Reduced \\
\hline R. Gastrocn (Med) & $N$ & None & None & None & None & $2+$ & $1+$ & $2+$ & Reduced \\
\hline L. Vast. Lateralis & $N$ & None & None & None & None & $N$ & $N$ & $N$ & Sub Interference \\
\hline R. Vast. Lateralis & $N$ & None & None & None & None & $N$ & $\mathrm{~N}$ & $N$ & Sub Interference \\
\hline
\end{tabular}

Abbreviation of Muscles. L. Tib Anterior, Left Tibialis Anterior muscle; L. Ext. Dig. Brevis, Left Extensor Digitorum Brevis muscle; R. Ext. Dig. Brevis, Right Extensor Digitorum Brevis muscle; L. Gastrocn (Med), Left Gastrocnemius muscle medial; R. Gastrocn (Med), Right Gastrocnemius muscle medial; L. Vast. Lateralis, Left Vastus Lateralis muscle; R. Vast. Lateralis, Right Vastus Lateralis muscle. Abbreviation of examination. Spontaneous IA; Spontaneous Fib., Fibrillation; Spontaneous PSW, PolySpike Waves; Spontaneous Fasc., Fasciculations; Spontaneous H.F., High Frequency; MUAP, Motor Unit Action Potential; Amp., Amplitude; Dur., Duration; PPP, PolyPhasic Potential - Recruitment Pattern. Abbreviation Results: N, Normal.

\section{DISCUSSION}

The respiratory system is the most commonly affected by SARSCoV-2, but other organ manifestations have been described involving the heart, kidney, and gastrointestinal system. Previous data indicate that the virus is capable of causing an excessive immune reaction with an increased level of cytokines, such as Interleukin-6 (IL-6) $(5,21)$. It seems that these immunological processes stimulate an inflammatory cascade, leading to extensive tissue damage, including of the nervous system, with variable clinical implications (3). To date, there is no evidence that SARS$\mathrm{CoV}-2$ is highly neurovirulent (4), though neurological signs, such as nausea, vomiting, myalgia, dizziness (6), hypogeusia, hyposmia, and impaired consciousness (22), were observed as first symptoms. According to other findings, the body's innate and adaptive immune responses to infection as well as the virus itself could be responsible for both central and peripheral neurological damage (4). With regard to the peripheral nervous system (PNS), GBS is an immune-mediated disease; although mechanisms for coronavirus PNS disease are not 
TABLE 2 | Results of motor and functional assessment.

\begin{tabular}{|c|c|c|c|c|c|c|c|}
\hline & $\begin{array}{c}\text { MRS } \\
\text { (points) }\end{array}$ & $\begin{array}{c}\text { MBI } \\
\text { (points) }\end{array}$ & $\begin{array}{c}\text { TCT } \\
\text { (points) }\end{array}$ & $\begin{array}{l}\text { SPPB } \\
\text { (points) }\end{array}$ & $\begin{array}{c}\text { BBS } \\
\text { (points) }\end{array}$ & $\begin{array}{c}\text { TUG } \\
\text { (seconds) }\end{array}$ & $\begin{array}{c}\text { 6MWT } \\
\text { (meters) }\end{array}$ \\
\hline \multicolumn{8}{|l|}{ TIMING } \\
\hline T0 (May 7, 2020) & $5 / 5$ & $19 / 100$ & $36 / 100$ & $0 / 12$ & $8 / 56$ & N.E. & N.E. \\
\hline $\begin{array}{l}\text { T1 (June 10, 2020) } \\
(4 \mathrm{WW}+\mathrm{AFO})\end{array}$ & $3 / 5$ & $46 / 100$ & $100 / 100$ & $3 / 12$ & $31 / 56$ & 22 & 237 \\
\hline $\begin{array}{l}\text { T2 (July 20, 2020) } \\
\text { (AFO) }\end{array}$ & $1 / 5$ & $100 / 100$ & $100 / 100$ & $12 / 12$ & $50 / 56$ & 10 & 345 \\
\hline \multicolumn{8}{|c|}{ RELIABLE CHANGE } \\
\hline T0-T1 & N.E. & $\begin{array}{c}\mathrm{SEM}=1.45(17) \\
\mathrm{RC}=18.05\end{array}$ & N.E. & $\begin{array}{c}\mathrm{SEM}=1.42(18) \\
\mathrm{RC}=5.53\end{array}$ & $\begin{array}{c}\mathrm{SEM}=2.93(19) \\
\mathrm{RC}=5.56\end{array}$ & N.E. & N.E. \\
\hline T1-T2 & N.E. & $\begin{array}{l}\mathrm{SEM}=1.45 \\
\mathrm{RC}=31.22\end{array}$ & N.E. & $\begin{array}{c}\mathrm{SEM}=1.42 \\
\mathrm{RC}=4.48\end{array}$ & $\begin{array}{c}\mathrm{SEM}=2.26 \\
\mathrm{RC}=5.94\end{array}$ & $\begin{array}{c}\mathrm{SEM}=1.14(20) \\
\mathrm{RC}=7.45\end{array}$ & $\begin{array}{c}\mathrm{SEM}=22(18) \\
\mathrm{RC}=3.47\end{array}$ \\
\hline
\end{tabular}

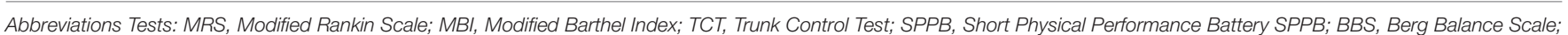
TUG, Time-Up and Go; 6MWT, 6 Minutes Walking Test. Abbreviations Aids: 4WW, four-wheeled walker; AFO, Ankle-Foot Orthoses. Abbreviation Result: N. E., Not Executable. Abbreviation Statistic: $R C$, Reliable Change method calculated as $R C=x t 1-x t 2 / S d i f f ; ~ S d i f f=\sqrt{ } 2\left(S E M^{2}\right)$ - SEM, standard error measurement. The value is attributed considering: SPPB (Older Adults), 6MWT and MBI (Stroke), BBS (Stroke; TO-T1 individuals who ambulate with assistance; T1-T2 individuals who ambulate independently).

well understood, viral infection is likely to cause an immune response and a pro-inflammatory state that results in dysimmune disorders including GBS. GBS associated with SARS-CoV2 might follow the pattern of a para-infectious mechanism, instead of the classic post-infectious profile, as reported in GBS associated with the Zika virus (23). The mechanisms of CNS vascular disease related to coronavirus are probably more complex and multifactorial. The main mechanism is linked to a pro-inflammatory state with consequent activation of thrombotic pathways and microvascular damage. Stroke can result from other mechanisms: an acute infection can trigger atrial fibrillation or endothelial dysfunction can lead to vascular complications. An involvement of brain parenchyma by the virus is also possible. Finally, similarly to what happens to other viruses (e.g., varicella zoster), immune response and pro-inflammatory status related to coronavirus-types can result in a vasculitic process (4). Regarding vasculitis lesions, histologic evidence has been reported in many organs such as the lung, liver, kidney, or skin of patients with COVID-19 (24-26), but cerebral vessels have not yet been investigated. To our knowledge, a single case report about COVID-19 and complications with a CNS vasculitis-like pattern was published, showing extensive cerebral small-vessel ischemic lesions resembling cerebral vasculitis (2). On the other hand, it is known that the prevalence and degree of cerebral white matter lesions increased with age (27). What we observed in our case is that brain lesions might have a different pathogenesis. The cerebral ischemic lesions were acute (restricted diffusion in MRI), multiple, and in different vascular territories and in cortical locations; considering the number of acute ischemia it is unlikely that they could originate from an atheromatous mechanism while, conversely, the small size makes an embolic cause unlikely. It might be considered that the pattern may be suggestive of a vasculitic origin: considering the association with both another dysimmune disease and SARS$\mathrm{CoV}-2$, we could speculate that the viral infection could have caused a dysimmune-response involving the nervous system, as described below. Diagnosis of SARS-CoV-2 infection of our patient was made at admission to the hospital and, primarily, he was treated with respiratory support and drugs, as referenced above. Neurological involvement appeared 14 days later and it was revealed by an acute and severe onset with cognitive impairment and flaccid, areflexic quadriplegia. Considering the temporal association, we can conjecture that SARS-CoV-2 may have contributed to the development of GBS in this patient. One article reported the interval of 5-10 days between the onset of viral illness and the first symptoms of GBS for five patients (28). This time is similar to the interval seen with GBS that occurs during or after other infections (29). Many case report series described increased GBS incidences (up to more than 5 times higher than expected) in COVID-19 affected areas (28). However, some limitations are worth noting. This syndrome was difficult to explore, probably because of the rarity of clinical manifestations. Furthermore, the alternative explanation that the patient coincidentally developed GBS of an unknown cause should be considered. The assumption is that the viral infection might have caused a dysimmune response involving both the PNS and CNS. Indeed, CNS involvement may also be determined by a dysimmune mechanism, with ischemic lesions of possible vasculitic origin, with a monophasic course. Excellent response to Intravenous Immunoglobulin ( $\mathrm{IgG}$ ) is consistent, although not conclusive with the hypothesis. A quick recovery of clinical status was stimulated with early rehabilitation. We applied several measurements for different skills. More specifically, MRS was used to evaluate general motor improvement; TCT, SPPB, and BBS was used for balance ability. TUG and 6MWT was used to assess walking speed, MBI was used for independence in ADLs. In particular, we observed a progressive strength recovery, primarily in upper limbs, hand grip, and manual skills. Upright position was restored in about 30 days. As expected, the clinically significant improvement of lower-limb muscle strength, as well as walking ability, occurred during the rehabilitation time. At the same time, this better clinical status led to significant 
improvements in mood and well-being, as well as a significant reduction in anxiety.

Because measuring change in outcome evaluations in an individual can be used to address both statistical and clinical significance, we applied the Reliable Change (RC) index, proposed by Jacobson and Truax in 1991 (30, 31). $\mathrm{RC}$ index indicates whether an individual change score is statistically significantly greater than a difference that could have occurred due to random measurement error alone (32). It is computed by dividing the difference between the pre-treatment $(\mathrm{Xt1})$ and post-treatment (Xt2) scores by the standard error of the difference (Sdiff) between the two scores.

$$
\mathrm{RC}=\mathrm{xt} 1-\mathrm{xt} 2 / \mathrm{Sdiff} \operatorname{Sdiff}=\sqrt{ } \mathbf{2}\left(\mathrm{SEM}^{2}\right)
$$

If the $\mathrm{RC}$ is $>1.96$, then the difference is reliable; a change of that magnitude would not be expected due to the unreliability of the measure? Conversely, if the RC score is 1.96 or less then the change is not considered to be reliable, it could have occurred just due to the unreliability of the measurement. $\mathrm{RC}$ index requires knowledge of distribution scores for the normal and disordered populations under scrutiny $(33,34)$, and, unfortunately, in the case of GBS these data are not known. Nonetheless, considering similar populations affected by neurological disease (e.g., stroke), the standard error measurement (SEM) is calculated for some of the scales we administered. As shown in Table 2, RC was calculated for 6MWT, TUG, BBS, SPPB, and MBI. These results are clinically and statistically significant. For TCT and MRS a $30 \%$ change from baseline might be considered as a clinically meaningful improvement for individual patients, comparing measurements at different follow-ups (35).

An additional consideration is about walking speed at discharge $(3.45 \mathrm{Km} / \mathrm{h})$. It was higher compared to one other reported by Novak et al. (36) in GBS $(2.8 \mathrm{~km} / \mathrm{h})$, but lower considering the normal walking speed for men aged between 60 and 69 years $(4.82-5.16 \mathrm{Km} / \mathrm{h})(37)$.

In summary, in this case report we have reported the clinical history of a patient who suffered from peripheral (GBS) and central (vasculitis) neurological involvement at one time, and then later from SARS-CoV-2 infection. We have only hypothesized a possible association between infection and neurological symptoms. Further studies should be conducted to support a causal relationship and better understand this possible link. Quick detection of neurological symptoms and diagnosis are fundamental to set up the appropriate therapy. IgG infusion allowed the patient to benefit considerably from early rehabilitation, achieving walking, increasing independence

\section{REFERENCES}

1. Hernández-Fernández F, Sandoval Valencia $H$, Barbella-Aponte RA, Collado-Jiménez R, Ayo-Martín Ó, Barrena C, et al. Cerebrovascular disease in patients with COVID-19: neuroimaging, histological and clinical description. Brain. (2020) 143:3089-103. doi: 10.1093/brain/ awaa239 in daily living tasks, and enabling safe discharge from hospital to home. The patient was fully aware of the seriousness of his illnesses, especially in the early stages, characterized by a long time spent in the ICU due to severe pneumonia then was made even worse by the tetraplegia. Loss of autonomy (poorly tolerated by the patient) and removal from the family, necessary due to the infectious state, contributed to the worsening of the mood. Muscle strength recovery and consequent autonomy in ADLs gave the patient a positive emotional boost, strengthened by reuniting with relatives after COVID-19 restrictions imposed during hospitalization in the Rehabilitation Unit relaxed. At discharge he expressed his happiness recognizing the efficacy of drug therapies and rehabilitation treatments.

\section{DATA AVAILABILITY STATEMENT}

The original contributions presented in the study are included in the article/Supplementary Materials, further inquiries can be directed to the corresponding author/s.

\section{ETHICS STATEMENT}

Ethical review and approval was not required for the study on human participants in accordance with the local legislation and institutional requirements. The patients/participants provided their written informed consent to participate in this study. Written informed consent was obtained from the participant for the publication of any potentially identifiable images or data included in this article.

\section{AUTHOR CONTRIBUTIONS}

SC wrote the first draft, was responsible for data collection, performed data interpretation. LS performed the literature search and revised data interpretation. FG performed data interpretation and the literature search. AI prepared Figure 2, performed data analysis, and interpretation. GB revised data interpretation. DD conceived the study, prepared Figure 1/ Supplementary Material, performed statistical analysis, revised data interpretation, and the final manuscript. All authors contributed to the article and approved the submitted version.

\section{SUPPLEMENTARY MATERIAL}

The Supplementary Material for this article can be found online at: https:/www.frontiersin.org/articles/10.3389/fneur. 2020.602554/full\#supplementary-material 
4. Ellul MA, Benjamin L, Singh B, Lant S, Michael BD, Easton A, et al. Neurological associations of COVID-19. Lancet Neurol. (2020) 19:767-83. doi: 10.1016/S1474-4422(20)30221-0

5. Helms J, Kremer S, Merdji H, Clere-Jehl R, Schenck M, Kummerlen C, et al. Neurologic features in severe SARS-CoV-2 infection. N Engl J Med. (2020) 382:2268-70. doi: 10.1056/NEJMc2008597

6. Wang D, Hu B, Hu C, Zhu F, Liu X, Zhang J, et al. Clinical characteristics of 138 hospitalized patients with 2019 novel coronavirus-infected pneumonia in Wuhan, China. JAMA. (2020) 323:1061-9. doi: 10.1001/jama.2020.1585

7. Walgaard C, Lingsma HF, Ruts L, van Doorn PA, Steyerberg EW, Jacobs BC. Early recognition of poor prognosis in Guillain-Barre syndrome. Neurology. (2011) 76:968-75. doi: 10.1212/WNL.0b013e3182104407

8. Yamagishi Y, Suzuki H, Sonoo M, Kuwabara S, Yokota T, Nomura K, et al. Markers for Guillain-Barré syndrome with poor prognosis: a multi-center study. J Peripher Nerv Syst. (2017) 22:433-9. doi: 10.1111/jns.12234

9. Compston A. Aids to the investigation of peripheral nerve injuries. Medical Research Council: Nerve Injuries Research Committee. His Majesty's Stationery Office: 1942; pp. 48 (iii) and 74 figures and 7 diagrams; with aids to the examination of the peripheral nervous system. By Michael O'Brien for the Guarantors of Brain. Saunders Elsevier: 2010; pp. [8] 64 and 94 Figures. Brain. (2010) 133:2838-44. doi: 10.1093/brain/awq270

10. Quinn TJ, Dawson J, Walters MR, Lees KR. Exploring the reliability of the modified rankin scale. Stroke. (2009) 40:762-6. doi: 10.1161/STROKEAHA.108.522516

11. Mahoney FI, Barthel DW. Functional evaluation: the Barthel index. Md State Med J. (1965) 14:61-5. doi: 10.1037/t02366-000

12. Franchignoni FP, Tesio L, Ricupero C, Martino MT. Trunk control test as an early predictor of stroke rehabilitation outcome. Stroke. (1997) 28:1382-5. doi: 10.1161/01.STR.28.7.1382

13. Guralnik JM, Simonsick EM, Ferrucci L, Glynn RJ, Berkman LF, Blazer DG, et al. A short physical performance battery assessing lower extremity function: association with self-reported disability and prediction of mortality and nursing home admission. J Gerontol. (1994) 49:M85-94. doi: 10.1093/geronj/49.2.M85

14. Berg K, Wood-Dauphinee S, Williams JI. The balance scale: reliability assessment with elderly residents and patients with an acute stroke. Scand $J$ Rehabil Med. (1995) 27:27-36.

15. Podsiadlo D, Richardson S. The timed "up \& go": a test of basic functional mobility for frail elderly persons. J Am Geriatr Soc. (1991) 39:142-8. doi: 10.1111/j.1532-5415.1991.tb01616.x

16. ATS Committee on Proficiency Standards for Clinical Pulmonary Function Laboratories. ATS statement: guidelines for the six-minute walk test. Am J Respir Crit Care Med. (2002) 166:111-7. doi: 10.1164/ajrccm.166.1.at1102

17. Hsueh IP, Lee MM, Hsieh CL. Psychometric characteristics of the Barthel activities of daily living index in stroke patients. J Formos Med Assoc. (2001) 100:526-32.

18. Perera S, Mody SH, Woodman RC, Studenski SA. Meaningful change and responsiveness in common physical performance measures in older adults. J Am Geriatr Soc. (2006) 54:743-9. doi: 10.1111/j.1532-5415.2006. 00701.x

19. Stevenson TJ. Detecting change in patients with stroke using the Berg Balance Scale. Aust J Physiother. (2001) 47:29-38. doi: 10.1016/S00049514(14)60296-8

20. Flansbjer UB, Holmbäck AM, Downham D, Patten C, Lexell J. Reliability of gait performance tests in men and women with hemiparesis after stroke. $J$ Rehabil Med. (2005) 37:75-82. doi: 10.1080/16501970410017215

21. Carod-Artal FJ. Neurological complications of coronavirus and COVID-19. Rev Neurol. (2020) 70:311-22. (English, Spanish). doi: 10.33588/rn.7009.2020179

22. Mao L, Jin H, Wang M, Hu Y, Chen S, He Q, et al. Neurologic manifestations of hospitalized patients with coronavirus disease 2019 in Wuhan, China. JAMA Neurol. (2020) 77:683-90. doi: 10.1001/jamaneurol.2020.1127
23. Zhao H, Shen D, Zhou H, Liu J, Chen S. Guillain-Barré syndrome associated with SARS-CoV-2 infection: causality or coincidence? Lancet Neurol. (2020) 19:383-4. doi: 10.1016/S1474-4422(20)30109-5

24. Xu Z, Shi L, Wang Y, Zhang J, Huang L, Zhang C, et al. Pathological findings of COVID-19 associated with acute respiratory distress syndrome. Lancet Respir Med. (2020) 8:420-2. doi: 10.1016/S2213-2600(20)30076-X

25. Yao XH, Li TY, He ZC, Ping YF, Liu HW, Yu SC, et al. A pathological report of three COVID-19 cases by minimal invasive autopsies. Zhonghua Bing Li Xue Za Zhi. (2020) 49:411-7. (Chinese). doi: 10.3760/cma.j.cn112151-20200312-00193

26. Varga Z, Flammer AJ, Steiger P, Haberecker M, Andermatt R, Zinkernagel AS, et al. Endothelial cell infection and endotheliitis in COVID-19. Lancet. (2020) 395:1417-8. doi: 10.1016/S0140-6736(20)30937-5

27. de Leeuw FE, de Groot JC, Achten E, Oudkerk M, Ramos LM, Heijboer $\mathrm{R}$, et al. Prevalence of cerebral white matter lesions in elderly people: a population based magnetic resonance imaging study. The Rotterdam Scan Study. J Neurol Neurosurg Psychiatry. (2001) 70:9-14. doi: 10.1136/jnnp. 70.1 .9

28. Toscano G, Palmerini F, Ravaglia S, Ruiz L, Invernizzi P, Cuzzoni MG, et al. Guillain-Barré syndrome associated with SARS-CoV-2. N Engl J Med. (2020) 382:2574-6. doi: 10.1056/NEJMc2009191

29. Wijdicks EF, Klein CJ. Guillain-Barré syndrome. Mayo Clin Proc. (2017) 92:467-79. doi: 10.1016/j.mayocp.2016.12.002

30. Unicomb R, Colyvas K, Harrison E, Hewat S. Assessment of reliable change using 95\% credible intervals for the differences in proportions: a statistical analysis for case-study methodology. J Speech Lang Hear Res. (2015) 58:72839. doi: 10.1044/2015_JSLHR-S-14-0158

31. Jacobson NS, Truax P. Clinical significance: a statistical approach to defining meaningful change in psychotherapy research. J Consult Clin Psychol. (1991) 59:12-9. doi: 10.1037/0022-006X.59.1.12

32. Iverson GL. Reliable change index. In: Kreutzer J, DeLuca J, Caplan B, editors. Encyclopedia of Clinical Neuropsychology. Cham: Springer (2019).

33. Bothe AK, Richardson JD. Statistical, practical, clinical, and personal significance: definitions and applications in speech-language pathology. Am J Speech Lang Pathol. (2011) 20:233-42. doi: 10.1044/1058-0360(2011/10-0034)

34. Lambert MJ, Hansen NB, Bauer S. Assessing the clinical significance of outcome results. In: Nezu AM, Nezu CM, editors. Evidence-Based Outcome Research: A Practical Guide to Conducting Randomized Controlled Trials for Psychosocial Interventions. New York, NY: Oxford University Press (2008). p. 359-78.

35. Ostelo RW, Deyo RA, Stratford P, Waddell G, Croft P, Von Korff M, et al. Interpreting change scores for pain and functional status in low back pain: towards international consensus regarding minimal important change. Spine. (2008) 33:90-4. doi: 10.1097/BRS.0b013e31815e3a10

36. Novak P, Šmid S, Vidmar G. Rehabilitation of Guillain-Barré syndrome patients: an observational study. Int J Rehabil Res. (2017) 40:158-63. doi: 10.1097/MRR.0000000000000225

37. Bohannon RW, Williams Andrews A. Normal walking speed: a descriptive meta-analysis. Physiotherapy. (2011) 97:182-9. doi: 10.1016/j.physio. 2010.12.004

Conflict of Interest: The authors declare that the research was conducted in the absence of any commercial or financial relationships that could be construed as a potential conflict of interest.

Copyright (c) 2021 Colonna, Sciumé, Giarda, Innocenti, Beretta and Dalla Costa. This is an open-access article distributed under the terms of the Creative Commons Attribution License (CC BY). The use, distribution or reproduction in other forums is permitted, provided the original author(s) and the copyright owner(s) are credited and that the original publication in this journal is cited, in accordance with accepted academic practice. No use, distribution or reproduction is permitted which does not comply with these terms. 